\title{
The future of simulation in medical education
}

\section{Dear Editor:}

Simulation has made significant in-roads into the provision of medical education over the past twenty years ${ }^{[1]}$. Simulation made its first impact in specialities such as emergency medicine and anaesthetics; however, it is now being used as an educational modality in a diverse range of specialities - from general practice to psychiatry. Perhaps the greatest pointer of the success of simulation is that it is now increasingly being seen as embedded in medical education and no longer something new and different. So now is probably an appropriate time to consider the future of simulation. Where will simulation go next? It is likely that a number of different themes will emerge.

Firstly, simulation will likely become much more closely linked to assessment in the future. Assessment in medical education has itself moved in the direction of assessment for learning and in this regard it will have a good test bed for this concept in simulation. The learner of the future will likely spend time in the simulator being continually assessed. The assessment may be by a person or by a machine. Regardless of this, the assessment will be against performance metrics that are important and that can be measured. In keeping with best practice generally in assessment, feedback will be continuous and specific to the task in hand.

Secondly, our vision of what constitutes simulation will change radically in the future. Currently simulation is often seen as a method of learning that can be defined by time and space. So a learner might spend a half-day in the local simulation suite learning a skill. In the future, the concept of simulation will become much more wide so that it captures a range of less well defined but equally effective activities. For example, mobile simulation suites will enable simulation to happen on the wards or in the outpatient department ${ }^{[2]}$. Online simulations will enable learners to interact

Received 13 October 2014, Accepted 12 November 2014, Epub 02 March 2015 with simulations at a time and place that suits them ${ }^{[3]}$. Simulation centres themselves will become open access so that learners can use them as and when they wish to. Small teams will do simulations in the workplace without any technology - after all a table and chairs are sometimes enough to do simple general practice simulations.

What will happen to the cost of simulation? Here it is more difficult to say - certainly, the cost of new technologies has fallen rapidly over the past number of years and the amount of technology that can be purchased for a given amount of funding has increased dramatically. However, on the other hand, the cost of education and medical education specifically has continued to rise. So what will happen to simulation - driven as it is by technology and education? The answer is uncertain. Market forces will likely drive the costs of physical simulators down. However, simulation will remain very much a person driven activity and the cost of the time of faculty who have outstanding content and educational skills will likely remain high. One thing that is certain, however, is that simulation will not escape the increasing scrutiny that is being given to cost and value in medical education more generally ${ }^{[4]}$. Champions of simulation will have to prove that simulation in whatever form offers value for money for a given spend ${ }^{[5]}$. At present, the payer of simulation is largely the healthcare and educational institutions and not the learner - whether that will remain the case in the future we will have to $\operatorname{see}^{[6]}$.

If technology and fidelity have been the bywords for simulation in the past ten years, then transfer is likely to a byword for the future. A high technology simulation experience might sound attractive, but if that experience does not enable transfer to the clinical context where new skills will be utilised, then the technology may well be wasted. A high fidelity simulation experience may 
also seem attractive, but similarly will only be worthwhile if the fidelity enables transfer. It may emerge that features other than technology and fidelity are important in transfer - such features might include doing the simulation with the same team that you are going to do the procedure with. If that is the case, then these and other similar features will emerge as key features that must come to the fore in simulation provision.

There is no question but that simulation practice will become more evidence based in the future and that new evidence will influence best practice in simulation. Studies of educational effectiveness will drive practice in simulation learning. Performance assessment using simulation will be subject to rigorous evaluation as to its validity, reproducibility, feasibility, acceptability to stakeholders and impact on learning and practice. As well as developing a more solid evidence base, simulation will also become more steeped in educational theory. According to Prideaux "much research about medical education proceeds devoid of theory" and this has certainly been the case in simulation research. In the future, those working within simulation will become much more mindful of the theoretical paradigm that underpins their research and their practice.

Lastly, the future of simulation in medical education will follow the same path as the future of healthcare. At present the future of healthcare (over the next twenty years at least) will mean more primary care, more chronic disease management, and more patient selfmanagement. Simulation in the past has often been based in high technology simulation resuscitation suites where tertiary care specialists have cared for sophisticated manikins with rare and complicated diseases. However, in the future, simulations will be based in community surgeries where general practitioners will learn in simulated surgeries in which they will practice caring for elderly patients with multiple chronic diseases. From a non-clinical perspective, themes in healthcare will include the need to drive productivity and at the same time to maintain patient safety and quality and to control costs. So the future may mean more boardroom simulations where clinical and managerial leaders are presented with scenarios where a secondary care hospital has a bed crisis and an overcrowded emergency room and there is a shortage of emergency room doctors. Alternatively, it might mean long term strategic simulations related to population health where primary care leaders are tasked with simulations in which they have to distribute health care resources equitably to a community and at the same time balance a restricted budget.

There are no doubt other themes that will emerge in the future. Healthcare has been a state of flux for some time and there is a feeling that it has entered an era of continuous change. Simulation will likely follow suit. We will have to move quickly to keep up.

Yours Sincerely,

Dr. Kieran Walsh, FRCPI, FHEA,

BMJ Learning,

BMJ Publishing Group,

BMA House, Tavistock Square,

London WClH 9JR,

UK,

Tel: 0207-3836550,

Fax: 0207-3836242,

E-mail: kmwalsh@bmjgroup.com.

\section{References}

[1] Kneebone R, Nestel D. Learning clinical skills - the place of simulation and feedback[J]. The Clinical Teacher, 2005,2(2):86-90.

[2] Kneebone R, Arora S, King D, et al. Distributed simulationaccessible immersive training[J]. Med Teach, 2010,32(1): 65-70.

[3] Walsh K, Dillner L. Launching BMJ learning[J]. BMJ, 2003,327(7423):1064.

[4] Walsh K, Rutherford A, Richardson J, et al. NICE medical education modules: an analysis of cost-effectiveness[J]. Educ Prim Care, 2010,21(6):396-398.

[5] Walsh K, Jaye P. Cost and value in medical education[J]. Educ Prim Care, 2013,24(6):391-393.

[6] Sandars J, Walsh K. A consumer guide to the world of e-learning[J]. Student BMJ, 206,14:221-264. 